\title{
Procurement and Contract Strategies for Construction
}


Downloaded by [] on [26/04/23]. Copyright @ ICE Publishing, all rights reserved. 


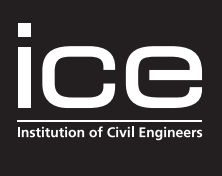

\section{Procurement and Contract Strategies for Construction}

lan Heaphy

FRICS FCIArb FClnstCES MACostE

IN Construction Consulting 
Published by ICE Publishing, One Great George Street, Westminster, London SW1P 3AA

Full details of ICE Publishing representatives and distributors can be found at: www.icebookshop.com/contact.aspx

\section{Other titles by ICE Publishing:}

NEC4: A User's Guide

Jon Broome. ISBN 978-0-7277-6205-4

FIDIC 2017 Contracts Companion - 3 vol set

Jakob B Sørensen. ISBN 978-0-7277-6448-5

Managing Reality, Third edition: Complete Set

Bronwyn Mitchell and Barry Trebes. ISBN 978-0-7277-6195-8

www.icebookshop.com

A catalogue record for this book is available from the British Library

ISBN 978-0-7277-6371-6

(C) Thomas Telford Limited 2022

ICE Publishing is a division of Thomas Telford Ltd, a wholly-owned subsidiary of the Institution of Civil Engineers (ICE).

All rights, including translation, reserved. Except as permitted by the Copyright, Designs and Patents Act 1988, no part of this publication may be reproduced, stored in a retrieval system or transmitted in any form or by any means, electronic, mechanical, photocopying or otherwise, without the prior written permission of the Publisher, ICE Publishing, One Great George Street, Westminster, London SW1P 3AA.

This book is published on the understanding that the author is solely responsible for the statements made and opinions expressed in it and that its publication does not necessarily imply that such statements and/or opinions are or reflect the views or opinions of the publishers. While every effort has been made to ensure that the statements made and the opinions expressed in this publication provide a safe and accurate guide, no liability or responsibility can be accepted in this respect by the author or publishers.

While every reasonable effort has been undertaken by the author and the publisher to acknowledge copyright on material reproduced, if there has been an oversight please contact the publisher and we will endeavour to correct this upon a reprint.

Cover photo: Foggy afternoon in Lisbon. Astrid S/Alamy Stock Photo.

Commissioning Editor: Michael Fenton Production Editor: Madhubanti Bhattacharyya

Marketing Specialist: April Brodie

Typeset by Academic + Technical, Bristol

Index created by Matthew Gale

Printed and bound in Great Britain by Henry Ling, Dorset 
1.1. Purpose and structure of the book

1.2. Structure and contents

1.3. What is procurement?

1.4. The procurement process

02

Defining client requirements and any constraints on the procurement strategy

2.1. Introduction

2.2. Business needs and constraints

2.3. Project-specific needs and constraints

03

Understanding the supply chain

04

Packaging strategy

4.1. Introduction

4.2. Single package - turnkey/EPC

4.3. Design, Build and Operate

4.4. Multiple packages

05

Design responsibility

25

5.1. Introduction

5.2. Client design

5.3. Design and build

5.4. Relative advantages and disadvantages of each option

06

\section{Engagement model}

6.1. Introduction

6.2. Traditional engagement model

6.3. Construction management/EPCM

6.4. Management contracting

6.5. Alliancing

6.6. Early contractor involvement/two-stage procurement

6.7. Frameworks

07

\section{Commercial model}

7.1. Introduction

7.2. Fixed-price lump sum

7.3. Remeasurement

7.4. Target cost

7.5. Cost-reimbursable

7.6. Comparison of the commercial models

7.7. Incentivisation mechanisms 
8.1. Introduction

8.2. Bespoke or standard forms of contract

71

8.3. Standard forms of construction contracts

09

Tender selection and contract award

9.1. Introduction

9.2. Legal obligations in procurement

77

9.3. The tender process

Bibliography

Index 


\section{About the author}

Ian Heaphy has over 25 years of experience in the construction industry, including aviation, oil and gas, rail, water, highways and building.

He has worked with clients across the UK, Europe, Middle East, Far East, North America and Australia including government bodies, private employers and contractors.

Ian is a chartered Quantity Surveyor and has extensive experience in commercial and contract administration and project and programme management.

He specialises in the development and implementation of innovative procurement strategies with particular expertise around partnering, alliancing and target cost contracts.

Ian is a member of the NEC4 Contract Board and one of the authors responsible for developing and drafting the latest generation of NEC contracts.

Ian regularly facilitates workshops and delivers training in contract forms and procurement and contract strategies. He also frequently speaks at industry events and has had numerous articles published in construction journals.

In addition to his NEC and procurement work Ian also acts as adjudicator, dispute resolver and quantum Expert Witness. 